\title{
PERFORATION OF THE INTERVENTRICULAR SEPTUM IN MYOCARDIAL INFARCTION
}

\author{
BY \\ J. M. SWITHINBANK \\ From the Merthyr Tydfil and Aberdare Group of Hospitals, Merthyr Tydfil, Glamorgan \\ Received December 29, 1958
}

Rupture of the interventricular septum occurring as a complication of myocardial infarction has been reported with increasing frequency. The condition, at one time thought to be rare, is not uncommon and is of prognostic importance. It is, however, less common than rupture of the ventricular wall, for in a series of 698 cases of coronary occlusion, 6 per cent suffered from this latter complication (Bean, 1938). Prior to 1940 there were isolated reports of single cases, though Sager (1934) collected eighteen that had been reported, and Weber (1943) made a further review. Including the seven described here it is possible now to find reference to 113 cases.

Five of the cases of septal perforation described in this paper were diagnosed during life; one at necropsy, the correct diagnosis not having been made in life; and one was the subject of a coroner's post mortem, the patient being found dead. During the last seven years in which records are available in this hospital group, 219 men and 99 women have been seen with cardiographic evidence of salient cardiac infarction using standard criteria (Evans, 1954).

Case 1. An obese woman, aged 53, experienced the pain of myocardial infarction, severe enough to cause vomiting and sweating. She had had two years previously a left hemiparesis but had made a good recovery: she had been dyspnœic on effort for some years but had never had anginal pain on effort nor any history of a previous coronary occlusion. Her father had died of a cerebral vascular accident at the age of sixty eight.

She was seen by her own practitioner that evening who thought that she had had a myocardial infarction, and at that time she had no murmur. When seen the following morning she was cyanosed, her blood pressure was $80 / 70 \mathrm{~mm}$. $\mathrm{Hg}$, her apex beat five inches from the mid line in the fifth space, and over the whole of the præcordium there was a loud rough pansystolic murmur accompanied by a thrill; coarse crepitations were heard at the bases. She was admitted to hospital, and anticoagulant therapy commenced. With 1-noradrenaline her blood pressure rose to $90 / 80 \mathrm{~mm}$. $\mathrm{Hg}$, but her condition deteriorated, venous congestion appeared, and she died three days after the onset of pain. Her cardiogram (Fig. 1), showed an extensive anterior myocardial infarction with prominent S-T plateaux in leads V1 to V4.

Necropsy revealed a small amount of blood-stained pericardial fluid. The heart weighed $450 \mathrm{~g}$. , the left ventricle was large, and there was a recent infarct involving the apex and anterior wall of the left ventricle, the lower part of the interventricular septum was involved, and this had ruptured in its lower part. There was severe atheroma of the aorta and all the coronary vessels, and a recent thrombus was present in the descending branch of the left coronary artery. She had bilateral pulmonary œdema and a congested liver which weighed $1500 \mathrm{~g}$.

Case 2. A man, aged 63, had been dyspnœic on effort but without pain for about one year. On 8.3.54, while working in his garden he had a sudden attack of dyspnoea which occurred again about two days later; in neither of these attacks was there any pain or discomfort. On the evening after the second attack while reading in bed, he had a severe pain across the front of his chest, which lasted for only a minute or so, but was repeated at intervals throughout the night, each attack lasting only for a few minutes. He then remained free from pain for four days. On 14.3.54 he had a further attack which lasted for thirty minutes, and this time he vomited. During the next five days he felt exhausted but had no further pain. He had had no 
significant previous illnesses, and there was no special family history except that his son had died at the age of twenty-one from a cerebral hæmorrhage.

When seen on 19.3.54 no abnormal cardiac auscultatory signs were found, his blood pressure was 115/75: there was no systemic venous congestion, though moist sounds were heard at the lung bases. The following day he was admitted to hospital, anticoagulant therapy was commenced, and two days later the murmur and thrill of a ruptured interventricular septum were observed. He was now complaining of pain below the right costal margin, and his blood pressure was $110 / 70 \mathrm{~mm}$. Hg. Five days after admission he complained of increased dyspnœa, his blood pressure fell to $95 / 50 \mathrm{~mm}$. $\mathrm{Hg}$, but there had been no recurrence of chest pain. With 1-noradrenaline his blood pressure was maintained at about $115 / 95 \mathrm{~mm} . \mathrm{Hg}$ until 11.4.54 when there was a sudden fall of blood pressure and death occurred. From 27.3.54 till death he had intermittent hiccough (blood urea $125 \mathrm{mg}$. per $100 \mathrm{ml}$.), sacral œedema occurred on 2.4.54, and a right pleural effusion on 9.4.54. Anticoagulant therapy was given throughout his stay in hospital and his prothrombin index varied between 16 and 37 per cent.

Necropsy revealed an organizing pericarditis; the heart weighed $500 \mathrm{~g}$., and there was an infarct of the anterior wall of the left ventricle from base to apex, and this involved the anterior part of the interventricular septum which had ruptured midway between base and apex, the margins of the rupture being smooth. The descending branch of the left coronary artery was completely occluded at its origin and the circumflex branch showed atheromatous plaques one and three $\mathrm{cm}$. from its origin; there were also atheromatous changes in the right coronary artery. The liver weighed $1620 \mathrm{~g}$. and had a nutmeg appearance, the congested spleen weighed $240 \mathrm{~g}$., and there were bilateral pleural effusions and pulmonary oedema.

Case 3. A woman, aged 65, was admitted in a moribund condition. She had been cyanosed for two weeks, and had for some time been complaining of a constricting feeling in the chest, but she was unable to give an adequate history, and no independent history was available. On examination she had a loud rough systolic murmur over the whole of the præcordium, her blood pressure was $55 / 10 \mathrm{~mm}$. $\mathrm{Hg}$, and her liver was enlarged, with other signs of congrestive cardiac failure. Her condition deteriorated and she died thirty-four hours after admission.

Necropsy was restricted to the heart which weighed $450 \mathrm{~g}$.; there was a recent infarct of the anterior wall of the left ventricle which extended also to the right ventricle and involved the interventricular septum, which had perforated close to the apex. There was marked atheroma of all the coronary arteries, and a recent occlusion of the interventricular branch of the left coronary artery.

Case 4. A woman, aged 85, who lived alone was found dead in her house, nothing being known of the clinical history. At necropsy the heart weighed $500 \mathrm{~g}$., the left ventricle was large and there was a recent infarct of the posterior wall of the left ventricle and of the interventricular septum. There was a perforation in the lower part of the septum, and in addition there was a communication from the cavity of the right ventricle to the pericardial sac, causing a large hæmopericardium. There was severe atheroma of the coronary arteries, and a recent thrombus was present in the right circumflex branch. [One other example of rupture of the interventricular septum with associated ventricular wall rupture has been reported (Carrol, and Cummins, 1947).]

Case 5. A woman, aged 63, was a diabetic, taking 30 units of soluble insulin daily. For three days before, and on the day before admission, she had had attacks of pain in the centre of the chest with radiation to the left arm, which were associated with sweating. She had not previously had angina of effort, but had been dyspnoic on exertion. Her mother (who also had diabetes mellitus) had died at the age of 60 from a cerebral vascular accident, and her father had died at the age of 50 from a similar attack.

When admitted, she was not in cardiac failure, her blood pressure was $174 / 116 \mathrm{~mm}$. $\mathrm{Hg}$ and there was no cardiac murmur. Three hours after admission her blood pressure had fallen to $140 / 100 \mathrm{~mm}$., and the characteristic murmur of a ruptured interventricular septum could be heard; no thrill was felt. Her cardiogram showed changes of a posterior infarction. She died suddenly a few hours later. Necropsy showed a recent infarction in the interventricular septum which had ruptured, and marked atheroma of the coronary arteries. Gall stones were present in the gall bladder.

Case 6. A woman, aged 65, was admitted to hospital with a history of epigastric pain for one month, vomiting for one week, and more recently tenderness in the epigastrium. A clinical diagnosis of sub-acute pancreatitis was made. The serum amylase level was 537 Somogyi units. The white blood cell count of 34,000 per cu. ml. and the blood urea of $132 \mathrm{mg}$. per $100 \mathrm{ml}$. were thought to substantiate the diagnosis. It was noted during the examination that she had a loud rough left parasternal murmur, and the blood pressure of $90 / 65 \mathrm{~mm}$. $\mathrm{Hg}$ was attributed to the abdominal condition. She died three days after admission, no cardiogram having been recorded. 
Necropsy revealed a localized inflammatory change in the pancreas, no gall stones, an enlarged heart with normal valves, and a recent infarct of the left ventricle and the interventricular septum, which had ruptured leaving a communication $5 \mathrm{~mm}$. in diameter between the cavities.

The patient's own practitioner later stated that when he had examined her chest a fortnight before, no murmur had been heard.

Case 7. A man, aged 67, had attacks of pain in the centre of the chest, prior to admission to hospital. He was nearly moribund, his systolic blood pressure was less than $60 \mathrm{~mm}$. $\mathrm{Hg}$, and over the præcordium a loud systolic murmur and thrill were present. His practitioner stated that this murmur had not been present ten days before admission. The patient died within a few hours of admission. His cardiogram (Fig. 2) shows a very low voltage record with changes of anterior and posterior infarction. At necropsy the heart weighed $460 \mathrm{~g}$., all the coronary arteries were very atheromatous, and there was complete obliteration of part of the interventricular branch of the left coronary artery. There was a perforation in the anterior part of the interventricular septum which was $1 \mathrm{~cm}$. in diameter, and there was recent infarction of the anterior wall of the left ventricle, the interventricular septum and the posterior wall of the left ventricle. A large recent hæmorrhage had occurred in the medulla of the left adrenal gland; the cerebral arteries were atheromatous.

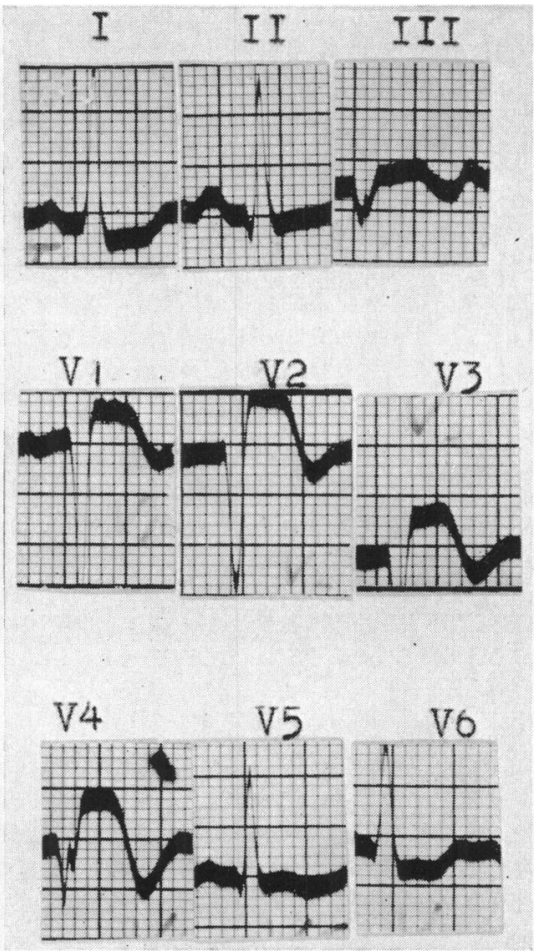

FIG. 1.-Cardiogram of Case 1. Extensive anterior infarction with QS complexes and elevation of S-T segments in III, V2, V3, and V4. Flat $T$ waves and $S-T$ segment depression in leads V5 and V6.

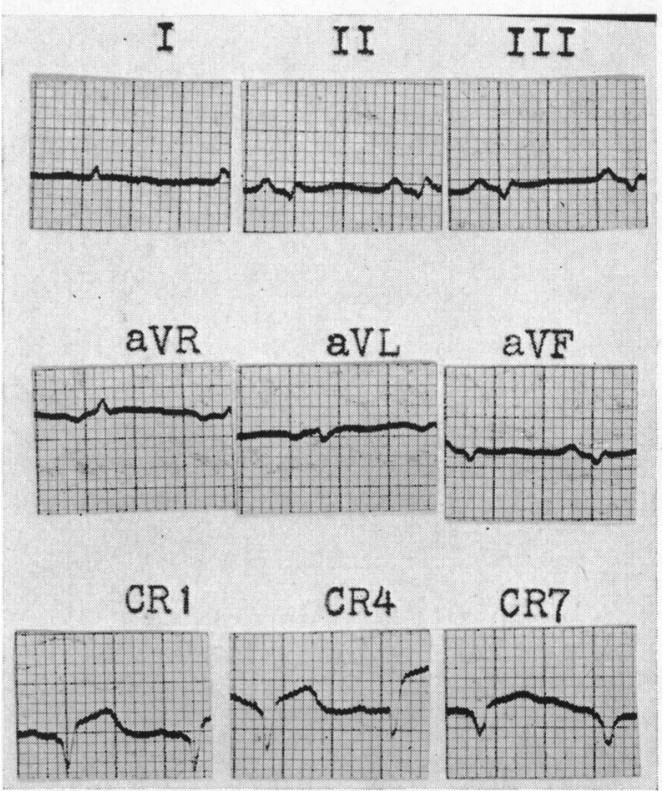

Fig. 2.-Cardiogram of Case 7. Extensive anterior infarction with QS complexes and elevation of the S-T segments in leads CR1, CR4, and CR7. Posterior extension shown by low voltage QR complexes in leads II, III, and VF. (The patient died within an hour of this recording.)

\section{DISCUSSION}

The clinical pattern of perforation of the interventricular septum is that of a patient who has had a myocardial infarct and suddenly develops a loud rough systolic murmur to the left of the sternum, maximal in the fourth intercostal space, perhaps with an accompanying thrill, with wide 
propagation of the murmur. Death usually follows within about two weeks, though there have been longer survivals. Some cases die very soon after the rupture, but in those who survive for about two weeks there is usually a phase of systemic venous congestion. This is in part perhaps due to the left-to-right ventricular shunt that occurs. Possibly, as suggested by Bernheim (1910), there is bulging of the weakened interventricular septum into the right ventricle. The diagnosis of this condition has been confirmed during life by cardiac catheterization (Muller et al., 1950), and also by alveolar gas analyses (Lian et al., 1946).

Other conditions to be considered in the differential diagnosis are four.

A pre-existing Ventricular Septal Defect. We have found no example of this difficulty having been reported. The diagnosis would depend on knowledge of the pre-existing lesion, the perforation would be in the upper rather than the lower part of the septum, and there would be absence of infarcted muscle tissue around the edges of the perforation.

Rupture of the Papillary Muscles. The systolic murmur here is similar, but there is often an associated diastolic murmur (Bailey and Rickman, 1944). Intractable pulmonary œdema also occurs (Schwarz and Canelli, 1957). It is also reported that in this condition the systolic murmur is maximal at the apex rather than the left parasternal region (Sanders et al., 1957).

Dilatation of the Left Ventricle with Mitral Regurgitation. The more gradual development of the murmur and its apical site would be of guidance here.

Intraventricular Thrombus Causing Mechanical Obstruction to the Mitral Valve. This has been described in a man of sixty-four by Soulié and Gerbeaux (1938). In this patient who had had an infarct of the anterior two-thirds of the septum the typical murmur and thrill of a perforation were found, but post mortem there had been no rupture of the septum the papillary muscles were intact, but there was a large thrombus that was interfering with closure of the mitral valve. A similar case is also reported in a man of 40 by Loeper et al. (1940).

The reports of septal perforation in myocardial infarction have previously been reviewed by Sager (1934), Weber (1943) and more recently by Malone and Parkes (1955). Their cases, together with those published by 62 other authors and the 7 described in this communication, bring the total recorded to 113 .

Table I summarizes those cases that are recorded fully enough to extract the relevant information. The average survival time from the occurrence of the perforation is two weeks. It is

TABLE I

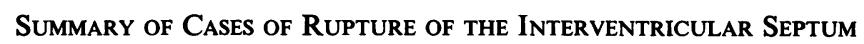

\begin{tabular}{|c|c|c|c|c|}
\hline & & & Men & Women \\
\hline Number .. & . & . & 58 & 33 \\
\hline Age range (years) & . & . & $34-87$ & $35-85$ \\
\hline Average age (years) & . & . & 61 & 65 \\
\hline $\begin{array}{l}\text { Average days survival } \\
\text { excluding these } 6 \\
\text { and } 2 \text { cases }\end{array}$ & $\begin{array}{l}\cdots \\
\cdots\end{array}$ & $\begin{array}{l}\cdots \\
\cdots\end{array}$ & $\begin{array}{l}15 \text { ( } 36 \text { cases }) \\
6,11,15,33, \text { months } \\
4 \text { and } 5 \text { years }\end{array}$ & $\begin{array}{l}13 \text { (22 cases) } \\
5 \text { and } 8 \text { months }\end{array}$ \\
\hline
\end{tabular}

difficult to determine the time interval between the infarction and the rupture, and in many cases several episodes of infarction have occurred before rupture of the septum resulted. In thirteen of the recorded cases in which accurate estimation of this time interval was possible there did not appear to be any correlation between the interval and the period of survival.

The systolic murmur, previously described, is a most important clinical feature; it was present in 67 out of 70 cases $(96 \%)$, the thrill was recorded in 34 out of 56 cases $(62 \%)$.

The site of perforation was in the lower part of the septum in 54 out of 82 cases $(66 \%)$, in the 
posterior part in 14 cases $(17 \%)$, in the middle part in 11 cases $(13 \%)$, and in the superior part in only 3 out of the 82 cases $(4 \%)$.

The size of the perforation varied from a pin hole to several centimetres, these larger measurements applying to linear tears. In five cases multiple perforations were present. Out of 46 cases recorded in detail the greatest measurement of the perforation exceeded $20 \mathrm{~mm}$. in 7 , was 10 to $19 \mathrm{~mm}$. in 23,5 to $9 \mathrm{~mm}$. in 6 , and less than $5 \mathrm{~mm}$. in 10 . There is, however, no correlation between the size of the rupture and the survival time.

Atheromatous changes were recorded as being common in the whole of the coronary system, the final occlusion being in the left coronary tree in 31 cases out of $40(77 \%)$, and in the right in 9 cases out of $40(23 \%)$. This preponderance of final occlusion in the left coronary system is not so well brought out by the cardiographic findings, for in 15 cases anterior infarcts were recorded, in 2 lateral infarcts, and in 15 posterior infarcts. Additional cardiographic findings noted were complete heart block in 2 cases, varying degrees of lesser atrio-ventricular block in 3, and right bundlebranch block in 5 cases. From the reports it would appear that of 56 cases only 39 were diagnosed during life.

\section{CONCLUSIONS AND SummaRY}

Perforation of the interventricular septum following myocardial infarction is not very unusual. It occurs in patients who have extensive coronary artery atheroma. Its recognition should not be difficult, and the prognosis is very poor. It is not possible to say whether anticoagulant therapy will improve this prognosis, but in that the occurrence of a septal perforation is a measure both of the presence of extensive coronary artery disease and a recent large infarct the author considers the matter open to doubt. The reported cases have been reviewed, seven new ones added, and the clinical picture and differential diagnosis discussed. The main clinical significance of the condition lies in its prognostic value.

The author is indebted to Dr. D. Powell for the post-mortem report on Case 7, and to Dr. D. MacKinnon for the post-mortem reports on the other cases. The author would also like to thank the general practitioners who referred these patients, and various resident house officers for their help with them.

\section{REFERENCES}

Bailey, O. T., Rickman, J. B. (1944). Amer. Heart J., 28, 578.

Bean, W. B. (1938). Ann. intern. Med., 12, 71.

Bernheim (1910). Rev. Med., 30, 285.

Carrol, D., and Cummins, S. D. (1947). Amer. Heart. J., 34, 893.

Evans, B., and Anderson, W. F. (1952). Brit. Heart J., 14, 537.

Evans, W. (1954). Cardiography. 2nd ed., Butterworth, London.

Lian, C., Welti, J. J., Barriage, E., and Rousseau, G. (1946). Arch. Mal. Caur, 39, 163.

Loeper, M., Varaya, A., Lesobre, R., and Lesourd, M. (1940). Arch. Mal. Caur, 33, 237.

Malone, R. G. S., and Parkes, W. E. (1955). Brit. Heart J., 17, 448.

Muller, O., Hummerfelt, S., Rasmussen, H., and Storstein, O. (1950). Acta Cardiol, Brux., $5,633$.

Sager, R. V. (1934). Arch. intern. Med., 53, 140.

Sanders, R. J., Neubuerger, K. T., and Ravin, A. (1957). Dis. Chest., 31, 316.

Schwarz, H., and Canelli, F. R. (1957). Amer. Heart J., 40, 354.

Soulié, P., and Gerbeaux, J. (1938). Arch. Mal. Cour, 31, 625.

Weber, M. L. (1943). Ann. intern. Med., 19, 973. 